\title{
Comunicação e cultura: a construção de significados
}

\author{
Maria Aparecida Baccega \\ Livre-docente aposentada da USP. \\ Professora de pós-graduação da USP e da ESPM-SP. \\ E-mail: mabga@usp.br
}

Uma certa veneração, um respeito excessivo, praticamente uma reverência tem caracterizado a relação da sociedade com os meios. Percebe-se que há certo temor com relação a eles, pois são vistos, em geral, como a encarnação do mal. E o tempo que dedicamos à reflexão sobre eles tem sido usado para maldizê-los, negá-los, transformá-los na bruxaria maior de nossos tempos, responsabilizando-os pelas mazelas da sociedade: da falta de empregos à banalização da nudez, da manipulação do processo eleitoral à violência cotidiana.

Ocorre que, plantados em nossas vidas, tecendo com sua presença um dos mais fortes fios da cultura em que todos vivemos, a culpabilidade que lhes atribuímos apresenta-se sempre de forma pontual: os males são arrolados um a um, como se não formassem um conjunto, uma totalidade, como se não dialogassem entre si. Como se não tivessem relação com a sociedade como um todo. Ora estamos escandalizadamente falando da nudez, ora da "manipulação" em favor de um determinado candidato, ora da violência presente em programas de televisão ou de rádio. E, quando termina a novela que trazia as cenas de nudez, quando passam as eleições ou quando o programa sobre violência muda um pouco sua receita, desaparecem as críticas.

Desse modo, têm sido deixadas de lado questões fundamentais para que possamos entender melhor os meios de comunicação e, ao final, certamente apresentar propostas para modificá-los: qual o papel do Estado na contemporaneidade? Quais os direitos do cidadão? O que é ser cidadão no Brasil? Quem consegue ser cidadão? Que mudanças consideramos necessárias para uma sociedade mais justa? Qual o projeto de Estado que temos? Como os meios podem colaborar na construção desse projeto? Qual consideramos ser o papel da mídia na formação de homens que saibam que têm direitos e que consigam reivindicá-los?

Julgamos que é preciso tomarmos consciência de que os meios de comunicação não são sobrenaturais. Como diz Tornero, referindo-se à televisão (mas podemos ampliar para os meios em geral), eles têm de ser assumidos 
1. TORNERO, José Manuel. El desafio educativo de la televisión. Para compreender y usar el medio $(O$ desafio educativo da televisão. Para compreender e usar o meio). Barcelona: Paidós, 1994. p. 137.

2. LIPPMANN, Walter. Estereótipos. In: STEINBERG, Charles (Org.). Meios de comunicação de massa. São Paulo: Cultrix, 1970. p. 149.

3. BOSI, Ecléa. O tempo vivo da memória: ensaios de psicologia social. São Paulo: Ateliê, 2003. p. 114-115. por nós como na verdade são: construídos e sustentados por seres humanos. A televisão, diz Tornero, "se introduz - de modo mais ou menos imperativo - na sociedade. É um objeto que pode ser manipulado, orientado e transformado pelo coletivo de telespectadores que o usa" ${ }^{1}$. Para este autor, é preciso deixar de olhar os meios como se eles fossem deuses, como se ao nos relacionarmos com eles precisássemos olhar para o alto. É preciso "inverter o sentido desse olhar que dirigimos para cima e torná-lo um olhar dono de si mesmo, livre e soberano", diante das propostas dos meios.

E o olhar livre e soberano é característico do cidadão, é resultado de concepções de Estado que respeitem os indivíduos, que busquem que todos sejam cidadãos. Assim, é indispensável que, rapidamente, acrescentemos à pauta das discussões sobre os meios (nudez, violência, alienação etc.) o debate sobre qual é a sociedade que queremos, como o Estado deverá atuar para garantir os direitos básicos a fim de que todos sejam cidadãos. Aí incluído o papel dos meios.

\section{COMUNICAÇÃO: CONFIANÇA E TECNOLOGIA}

Por outro lado, não podemos esquecer que os meios de comunicação, com os avanços permitidos pela tecnologia, são constitutivos da cultura e servem de suporte à realidade contemporânea. E seus suportes tecnológicos se sucederam no processo histórico: imprensa escrita, rádio, televisão, cinema e computador. As três últimas telas, como os demais, convivendo harmoniosamente.

Quando nascemos, encontramos uma mídia predominante, uma história em processo. É como se estivéssemos tomando um trem que está vindo de muitas e muitas outras estações. Ele carregou milhões de pessoas que já realizaram, juntas, um sem-número de ações. Construíram um jeito de ser, de viver, de entender o tempo e a realidade cotidiana, de localizar-se no espaço. Entramos nesse trem, banhamo-nos nessa cultura.

As ações realizadas manifestaram-se numa pluralidade de sentidos registrados pelas palavras nos discursos. São essas palavras que usamos para nos comunicar. São elas que entregam "descrito" e "interpretado" pelas gerações anteriores o pequeno espaço do mundo que temos para viver. Já na década de 1920, o jornalista Lippmann escrevia: "Cada um de nós vive e trabalha numa pequena parte da superfície da Terra, move-se num círculo restrito e, das coisas que conhece, conhece intimamente apenas umas poucas. De qualquer acontecimento público que exerça amplos efeitos, na melhor das hipóteses, só vemos uma fase e um aspecto" 2 .

Ecléa Bosi, em O tempo vivo da memória ${ }^{3}$, ratifica: "O nosso círculo de experiência é limitado. O nosso espaço vivido no mundo é pequeno. Embora tenhamos a ilusão de participar intensamente desse mundo único que encerra os seres viventes, conhecemos, na verdade, um reduzido espaço dentro dele, e um caminho familiar pelo qual nos guiamos e onde repetimos nossos passos, entre a infinidade de caminhos oferecida a outros seres. [...] Conhecemos 
algumas pessoas, algumas coisas, alguns pedaços de paisagens, de ruas, alguns livros. Presenciamos alguns fatos, mas não presenciamos a maior parte dos fatos sobre os quais conversamos. Confiamos, porém, nas pessoas que viveram e presenciaram esses fatos, e o pensamento e o discurso quotidiano se alimentam dessa confiança social”.

E são essas pessoas, instituições, meios de comunicação, nos quais confiamos, que vão nos contar os acontecimentos, que vão nos comunicar os "fatos" que não vimos.

E que é comunicar?

Comunicar é contar a alguém alguma coisa; é ouvir de alguém alguma coisa. Pressupõe, portanto, o diálogo. Nós só falamos, só contamos alguma coisa quando temos algum interesse em contar e/ou supomos haver interesse (ou queremos "criar" esse interesse) da parte de quem ouve. Também é o interesse que nos dispõe a ficar ouvindo o que o outro tem a dizer. Logo, a comunicação procede de alguém (há alguém que fala), dirige-se para alguém (o outro) e procura persuadir, convencer (em maior ou menor grau).

Para que haja entendimento entre as partes, para que haja comunicação, é preciso que a linguagem seja "comum”, ou seja, que os indivíduos que participam desse diálogo sejam socialmente organizados, que tenham feito um "contrato" entre eles e instituído os significados. São essas significações que encontramos prontas, que chegaram até nós nos discursos carregados pelo trem. Este trem (a História), no qual embarcamos ao nascer, carrega, portanto, discursos que portam significações que nos são impostas e que temos condições de modificar no decorrer de nossa vida, através de nossa práxis. A mediação entre o homem e a realidade objetiva é exercida pelas linguagens, sobretudo pela linguagem verbal, pela palavra. É ela que porta, que carrega a "descrição" e a "interpretação" da realidade.

Essa "descrição" e "interpretação" referem-se não apenas à categorização de objetos materiais, como também a valores e estereótipos. Assim, em São Paulo, chamamos um dos cursos d'água que cortam a cidade de rio Tietê. Esse tipo de curso d'água, no Norte, será chamado de igarapé (ou seja, caminho d'água, rio pequeno), pois rio para eles é, por exemplo, o Amazonas, que tem um volume d'água muitas e muitas vezes maior. $\mathrm{Na}$ área dos valores, basta lembrarmos as palavras "índio" e "negro", cuja conceituação continua a ser extremamente preconceituosa em nossa sociedade.

Como lembra Couceiro de Lima, "toda representação negativa que se constrói na sociedade brasileira sobre o negro [e sobre o índio, acrescentamos nós], e que circula por ela, é captada, reelaborada e devolvida pela mídia com grande eficiência"4.

A comunicação é, portanto, da própria natureza do ser humano. O desenvolvimento da tecnologia possibilitou o surgimento de suportes que fazem com que "o que é dito" e/ou "mostrado" pelo outro chegue imediatamente aos nossos ouvidos, aos nossos olhos, modificando os conceitos de tempo e espaço, sobretudo na contemporaneidade.
4. COUCEIRO DE LIMA, Solange M. A publicidade e os símbolos raciais. Comunicação \& Educação, São Paulo: CCA/ECA-USP/ Moderna, n. 2, p. 91-93, jan./abr. 1995. 


\section{ARTIGOS NACIONAIS}

Este número da revista Comunicação $\mathcal{E}$ Educação teve o cuidado de selecionar três artigos de suportes tecnológicos diferentes: cinema, rádio e televisão.

$\mathrm{O}$ primeiro, O cinema e a formação docente: um diálogo sobre as questões de gênero, de Vera Helena Ferraz de Siqueira, Cristiane Maia de Oliveira e Júlio Oliveira Braga, aborda, através do cinema (à luz de três filmes clássicos: Chuvas de Verão, Julieta dos Espíritos e Viver sua Vida), questões de gênero e sexualidade, ajudando a trincar preconceitos e, quem sabe, abrir a discussão sobre os estereótipos referentes à sexualidade feminina.

Audioaula: o som como suporte pedagógico em sala de aula, de André Barbosa Filho, é o segundo artigo. Ele trata da importância do rádio para o êxito do desenvolvimento dos projetos pedagógicos, envolvendo professores, alunos e comunidade escolar. Apresenta também uma experiência levada à prática em São Paulo.

Ana Maria Camargo Figueiredo, em Literatura na televisão: história, memória e biografia, o terceiro artigo, discute a adaptação de textos literários para a televisão. Destaca, ainda, a questão das minisséries e, entre elas, Anarquistas, Graças a Deus, adaptação do livro de Zélia Gattai para a televisão.

\section{ARTIGO INTERNACIONAL}

Memória cotidiana e comunicação é o artigo de Fernando Barone, que trata da temática que tem sido uma das preocupações prioritárias no campo científico, com destaque para o da comunicação. Partindo de uma reflexão teórica interdisciplinar, o autor elabora um modelo, aplicado aos professores de ensino básico da região de Lisboa.

\section{ENTREVISTA}

O entrevistado deste número é Heródoto Barbeiro. Em "Não sou professor, não sou advogado, sou jornalista!", Maria Cristina Castilho Costa dialoga com o jornalista, abordando várias temáticas, entre as quais o papel da mídia no cotidiano da sala de aula.

\section{CRÍTICA}

Clóvis de Barros Filho e Arthur Meucci, em Da virtude à estratégia: os conflitos morais em A Grande Família, discorrem sobre os discursos morais desse seriado televisivo, fazendo um diálogo entre as posições de Lineu e as de Agostinho, personagens da série. 


\section{DEPOIMENTO}

Tatiana Belinky, em Uma amadora, do verbo amar... Paixão!, fala de sua vida como escritora, tradutora, adaptadora de livros infantis para a televisão, juntamente com seu marido Júlio Gouveia. O casal foi responsável pela primeira adaptação para TV do Sítio do Pica-pau Amarelo, de Monteiro Lobato.

\section{EXPERIÊNCIA}

Temas transversais para professores de Ciências é a colaboração que Luzenice Macedo Martins traz para os leitores de Comunicação Ė Educação. Trata-se de um projeto sobre o meio ambiente desenvolvido na Universidade Estadual do Vale do Acaraú, no Maranhão.

\section{POESIA}

Para este número trouxemos Paulo Leminski, com seus haicais. Romancista e poeta, Leminski deixou também uma vasta obra como letrista de música popular. Nasceu em 1944, em Curitiba, e morreu aos 45 anos de idade.

\section{SERVIÇOS}

O jornalismo de espírito público não pode ser "chapa-branca" é o texto de Eugênio Bucci, jornalista, que hoje preside a Radiobrás. Com a colaboração de Carlos Henrique Knapp e Isadora Grespan, Bucci discorre sobre os documentos para orientação jornalística, além da estrutura de operação e os diversos serviços prestados pela instituição.

\section{VIDEOGRAFIA}

Maria Ignês Carlos Magno, em Interdisciplinaridade nas possibilidades de leitura de Abril Despedaçado, apresenta algumas leituras possíveis do filme, tendo como base a importância da incorporação da mídia ao cotidiano pedagógico e a discussão da temporalidade das experiências humanas, estabelecendo um diálogo entre passado e presente, que é próprio da história.

\section{BOLETIM BIBLIOGRÁFICO}

Bibliografia sobre telenovela brasileira e Bibliografia sobre comunicação e educação trazem livros, teses e dissertações sobre a temática. Endereços úteis na internet apresenta um elenco de endereços que certamente colaborarão com as tarefas dos professores. 


\section{ATIVIDADES EM SALA DE AULA}

Ruth Ribas Itacarambi propõe projetos pedagógicos a serem desenvolvidos em sala de aula com alunos de Ensino Fundamental e Médio, utilizando-se dos artigos publicados neste número.

Resumo: O artigo destaca que é preciso entender que os meios de comunicação são feitos pelos homens e para os homens, dimensionando-os criticamente, encarandoos sem submissão e não os vendo como causas de todos os males da sociedade moderna. Para tanto, mostra a comunicação como diálogo, processo de inter-relação, de troca e de persuasão. As informações, os relatos e os conhecimentos são adquiridos sempre a partir dos fatos narrados e descritos, tendo como base fundamental a linguagem verbal.

Palavras-chave: linguagem verbal, estereótipo, comunicação e educação.
Abstract: This article highlights the necessity of understanding that media are made by men for men, must be dimensioned critically as well as approached without subjection, but not seen as the causes of all diseases in Modern Society. Thus, communication is shown as dialogue, process of inter-relation, exchange and persuasion. Information, narratives and knowledge are always acquired from narrated and described facts, which are founded on the verbal language.

Keywords: verbal language, stereotype, communication and education. 